INVESTIGACIÓN / RESEARCH

Recibido: 13/01/2015-----Aceptado: 27/02/2015-----Publicado: 15/03/2015

\title{
LA CONSTRUCCIÓN DE LA IMAGEN DE LA MUJER EN EL HUMOR GRÁFICO DEL SEMANARIO HERMANO LOBO (1972 - 1976)
}

Carla Garrido Zanón ${ }^{\mathbf{1}}$. Universidad de Valencia. España. carla.garrido@uv.es

\section{RESUMEN:}

La finalidad de esta investigación es analizar la construcción de la imagen de la mujer en el semanario de humor, Hermano Lobo. Con este objetivo, se analizan las viñetas publicadas en la revista desde mayo de 1972, momento en que aparece la publicación, hasta junio de 1976, fecha en que desaparece. A través de la visión del humor gráfico de Hermano Lobo, encontramos una figura de la mujer desplazada con escasa representación y relevancia. La mujer ejerce de figurante silenciado como acompañante y fiel apoyo del hombre como consecuencia de una sociedad de tradición androcéntrica. Esta investigación forma parte de la tesis doctoral El humor en los últimos años del franquismo e inicios de la transición democrático española: el caso de Hermano Lobo (1972-1976).

PALABRAS CLAVE: humor gráfico - franquismo - dictadura - hermano lobo mujer - España - revista.

\section{CONSTRUCTION OF THE IMAGE OF WOMAN IN THE GRAPHIC HUMOUR OF THE WEEKLY HERMANO LOBO (1972 - 1976)}

\section{ABSTRACT:}

The purpose of this research is to show the construction of the image of women in the humor weekly magazine, Hermano Lobo. To this end, we analyze the cartoons published in the magazine since May 1972 when the publication appears, until June 1976, when it disappears. From the perspective of humorous cartoons of Hermano Lobo analyzed, the woman represents a low relevance. Women exercise mute assistant, accompanies and supports the man. This research is part of the doctoral

\footnotetext{
${ }^{1}$ Carla Garrido Zanón. Estudiante de doctorado del Área de Periodismo. Desarrollando la tesis "EI humor en los últimos años del franquismo e inicios de la transición democrática española: el caso de Hermano Lobo (1972-1976)." Universidad de Valencia.

Correo: carla.garrido@uv.es
} 
thesis "The humour in the last years of Franco and beginning of Spanish democratic transition: the case of Hermano Lobo (1972-1976)".

KEY WORDS: graphic humour - Franco - dictatorship - hermano lobo - woman spain - weekly.

\section{INTRODUCCIÓN:}

\subsection{El humor como testigo de la historia}

La investigación se enmarca dentro del ámbito de la historia de la comunicación social que adopta la mirada de los medios de comunicación como testigos privilegiados de la época sobre la que focalizamos nuestra atención. A través de ellos, conocemos una visión de los acontecimientos de primera mano y su influencia sobre la sociedad en aquel momento y su legado hasta la actualidad. En este sentido, el objetivo del análisis es estudiar «los medios de comunicación y su relación con la historia cultural, política, económica o social a fin de esclarecer la recíproca influencia habida entre los medios de comunicación y el cambio social». (Gómez Mompart, 2008: p. 91-92).

El estudio viene matizado por un segundo factor clave: el humor. La perspectiva que tomamos para la investigación se centra en el análisis de «la elaboración discursiva y comunicación social vinculadas al acontecer histórico de una sociedad [...] como pintura o secuencia sutil o grotesca de la vida cívica y de las costumbres sociales de sus paisanos en cualquier época de la historia contemporánea». (Bordería Ortiz, Martínez Gallego y Gómez Mompart, 2010: p. 9).

La risa se convierte en un catalizador de hechos históricos, especialmente, en un momento de censura como el que se vivía entre 1972 y 1976 en España. Se trata de dar rienda suelta a la opinión con métodos más elaborados para esquivar las prohibiciones y dar voz a parte de la sociedad que se ve respaldada con estas viñeras, historietas o imágenes, en principio ficticias, de la sociedad del momento.

\subsection{Nuevas perspectivas del humor}

El enfoque supone una novedad porque resucita una publicación como Hermano Lobo sobre la que todavía no se ha profundizado como referente del humor tardofranquista. Existen publicaciones que hacen un repaso de los mejores contenidos e historia de la revista, estudios que han analizado otras publicaciones de humor de la época, así como medios generalistas. Recientemente la publicación ha sido abordada a través de una comunicación para un congreso por la profesora de la Universidad de Valencia, Dolors Palau. En dicha comunicación se plasmó la presencia de la Monarquía, Ejército e Iglesia en el semanario. El privilegio e interés en un estudio exhaustivo de Hermano Lobo reside en que aborda los últimos cuatro años del franquismo y supone una nueva ola de humoristas gráficos y periodistas.

\section{OBJETIVOS}


La finalidad de esta investigación es analizar la construcción de la imagen de la mujer en el humor gráfico del semanario, Hermano Lobo. Con este objetivo, se analizan las viñetas publicadas en la revista desde mayo de 1972, momento en que aparece la publicación, hasta junio de 1976, fecha en que desaparece.

\section{METODOLOGÍA}

El método de investigación utilizado para el análisis de las viñetas se centra en la observación de contenido e imagen. Partimos del esquema de análisis propuesto por el Grupo de investigación: Comunicación, Historia y Sátira de la Universidad de Valencia, adaptado a los objetivos concretos que perseguimos en este caso.

A través de esta ficha de análisis se establece una clasificación de las viñetas en función del tema tratado, para conocer cuáles son los aspectos que más interés despiertan en referencia a la mujer en el semanario de humor; se analiza su posición y relevancia dentro de la publicación, así como el modo de construir el humor de cada autor. Al mismo tiempo, se aborda el campo formal y semántico derivado del análisis de los elementos gráficos y textuales, así como su relación y la observación de las figuras retóricas empleadas. El análisis de completa con la visión moral de la pieza.

Se han revisado un total de 213 números de Hermano Lobo, ubicados entre mayo de 1972 y junio de 1976, de los que se han seleccionado 200 viñetas en las que aparece la figura de la mujer. Los humoristas gráficos Summers, Chumy Chúmez, Gila y Forges son los encargados principalmente de caricaturizar la figura femenina.

\section{DISCUSIÓN}

\subsection{Hermano lobo: una revista de humor dentro de lo que cabe}

El semanario de humor Hermano Lobo surge en 1972, enmarcado en los años finales del franquismo, y desaparece con la transición democrática, en el verano de 1976. Su principal promotor será Chumy Chúmez, que pretendía luchar contra el monopolio de la revista La Codorniz (1941 - 1978), con una publicación muy visual y ligera: gran volumen de ilustración gráfica combinado con artículos breves de calidad en un número de páginas reducido. La publicación imitó la forma de la revista de humor francesa, Charlie Hebdo. Summers, El Perich, Gila, Forges y Ops serían algunos de sus colaboradores gráficos del semanario junto a Chúmez. 


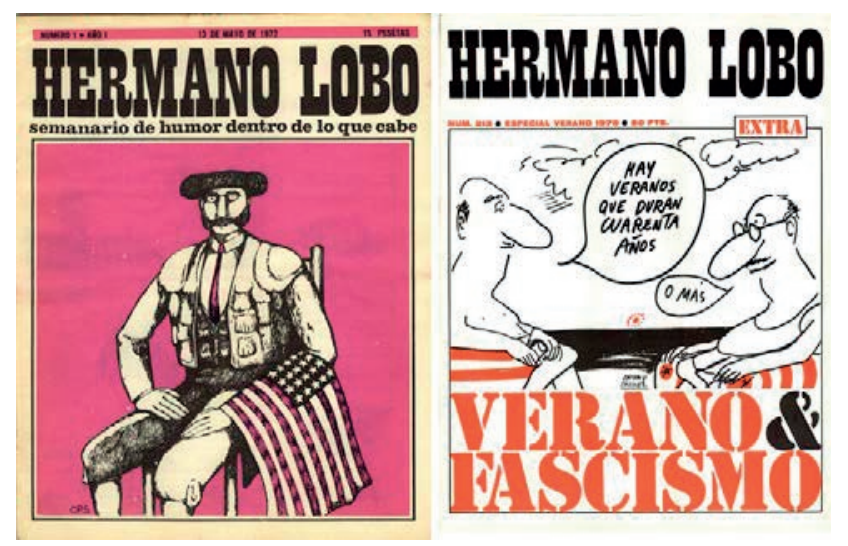

Imagen 1: Primera y última portada de Hermano Lobo (1972-1976).

Fuente: Hermano Lobo Digital.

Hermano Lobo trató los temas que se encontraban vigentes de la sociedad del momento a través de:

Un humor español de alta calidad agresiva. La revista cubría una necesidad: convertir en humor político por alusión indirecta lo que no se podía decir por las buenas» (Tubau, 1987: p. 242). La revista tenía como objetivo la calidad de las publicaciones con un número reducido de páginas que más tarde se ampliarían. Se pretendía que todo el contenido fuera «bueno, gracioso, aleccionador para el futuro de esperanzas que se aproximaba y a ser posible de izquierdas en su rama intelectual, afirmaba Chumy Chúmez (VV.AA, 1999: p.10).

La diferenciación se buscaba en la calidad y en su gran vocación política creando «una revista gráfica ilustrada por artículos breves distinguidos por su calidad literaria, su crítica a la sinrazón y su humor» (VV.AA, 1999: p.10).

La creación de cada una de las ilustraciones y textos de la revista Hermano Lobo obedecía a una voluntad de conexión con el lector, de que se adivinara la intencionalidad del autor, pero pasado por el filtro de la sutileza, para no chocar con la censura.

Había que hacer un esfuerzo importante para encontrar el chiste gráfico que provocase en el lector la misma intencionalidad que buscaba en el dibujante. Era un humor con autocensura, había que pensar más la idea y buscarle el truco necesario para que la censura no viera la intencionalidad que realmente llevaba, explicaba el humorista gráfico, Perich (Tubau, 1987: p. 244).

\subsection{La figura de la mujer en los años 70 en España}

En el periodo estudiado, finales del franquismo e inicios de la transición democrática, la mujer todavía ocupa una posición inferior al hombre, desplazada de numerosas actividades públicas con el objetivo de mantener un rol tradicional, es decir, una mujer que vive en matrimonio y se dedica a las labores del hogar. De hecho hasta el año 1976, «antes de que la mujer casada pudiese firmar cualquier documento (una 
cuenta corriente bancaria, un pasaporte, una escritura o un contrato de cualquier tipo), su marido tenía que firmar autorizándola a ello. Ésta era la figura de la licencia marital, que limitaba la capacidad de obrar de la mujer casada » (VVAA, 1999: p. 129).

Otro ejemplo del desplazamiento de la mujer era la llamada unidad de dirección que garantizaba que las decisiones con respecto a la familia se adoptaran bajo el único punto de vista del hombre, el cual, tenía esa potestad. Así, «el marido era el administrador único de los bienes de la sociedad de gananciales del matrimonio» (VVAA, 1999: p. 129).

No obstante, a partir de 1975, el movimiento feminista comienza a tener influencia en España. Asimismo, las mujeres habían comenzado a acceder al mercado laboral y las universidades. Ese mismo año, Naciones Unidas proclamó el Año Internacional de la Mujer, «era el primer paso para introducir los derechos de la mujer en todo el mundo» (vvaa, 1999: p. 136). Como consecuencia, una ley modificaría varios artículos del código civil y mercantil para "promover la igualdad entre los cónyuges» (Roig, 1989: p. 397).

\subsection{La mujer en el humor de hermano lobo}

Dentro de la revista de humor Hermano Lobo, encontramos una escasa relevancia de la figura de la mujer, confirmada por el bajo número de viñetas protagonizadas por personajes femeninos que hemos encontrado. En la mayoría de escenas, la mujer ejerce de figurante silenciado, simplemente acompañando y apoyando al hombre. Los roles que adopta la mujer en las diferentes piezas que se han analizado confirman su posición a la sombra del hombre en prácticamente la totalidad del material revisado. Respecto al rol de mujer objeto, se muestran dos tipos. Uno asociado a personajes femeninos que ejercen de esposas dedicadas a las labores del hogar y a sus hijos. El otro está representado a través de chicas jóvenes, vestidas de un modo más atrevido para la época, en las que los hombres piensan como objeto sexual.

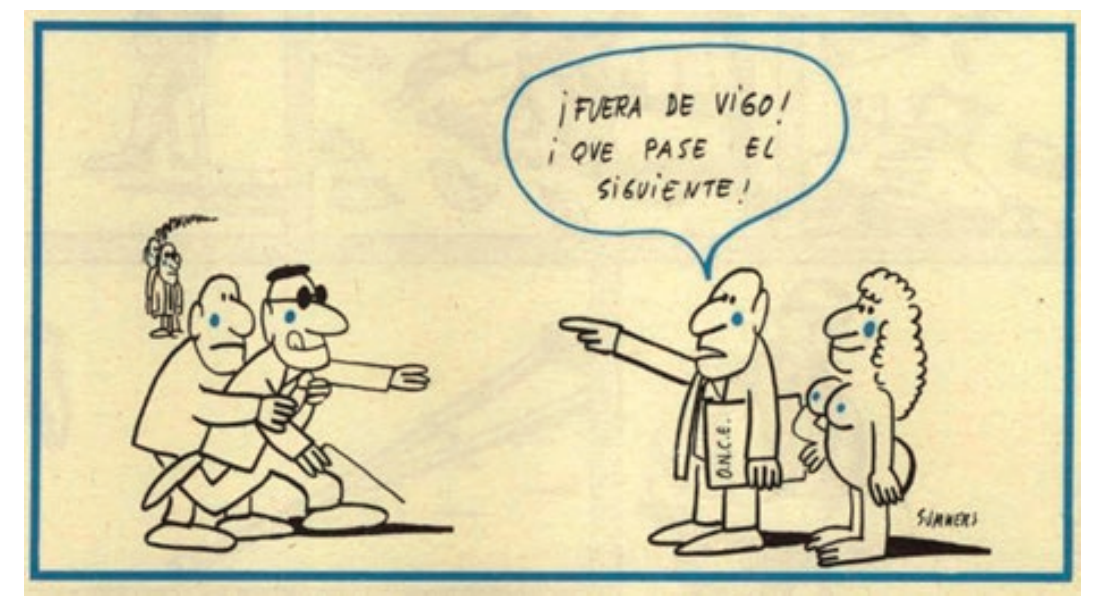

Imagen 2: La mujer ejerce un papel secundario y sin voz. Viñeta de Summers, 9 de febrero de 1972. Fuente: Hermano Lobo Digital. 
Esa imagen de esposa se repite en el caso de la mujer que juega el rol de madre. Normalmente se trata de mujeres desaliñadas, de mediana edad, que se dedican al cuidado de sus hijos, de su marido y de su casa. Muy relacionado con el rol de madre están los roles de ama de casa y de esposa hasta la muerte. El primero se presenta como la mujer dedicada a servir a un marido, el cual desprecia y critica la labor de ella. Este tipo de mujer se ubica en situaciones cotidianas contextualizadas en el hogar.

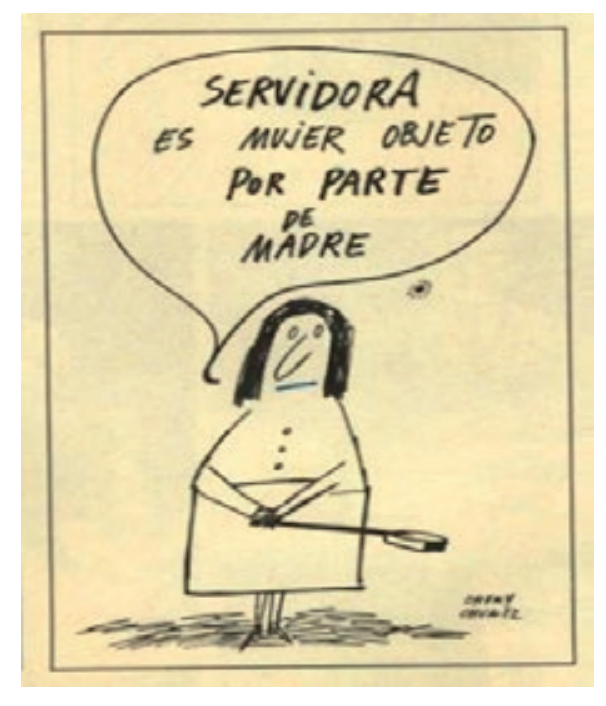

Imagen 3: La mujer ejerce de ama de casa, madre y esposa. Viñeta de Chumy Chúmez, 3 de marzo de 1973. Fuente: Hermano Lobo Digital.

En el rol de esposa hasta la muerte, la mujer se enfrenta a la violencia verbal y física del marido, con una gran dosis de humor negro, de la mano de autores como Chumy Chúmez o Gila. Estas situaciones desapacibles se dan dentro la institución del matrimonio, uno de los pilares del franquismo.

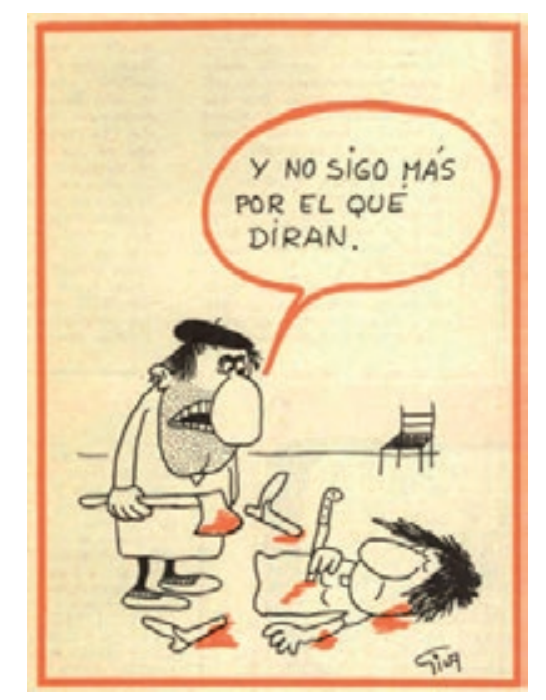

Imagen 4: Los humoristas muestran la violencia hacia la mujer dentro del matrimonio de manera explícita. Viñeta de Gila, 9 de junio de 1972. Fuente: Hermano Lobo Digital. 
Por último, cuando la mujer ocupa el rol de profesional, se limita a una serie de puestos de trabajo tradicionalmente asociados al género femenino representados como empleos que no requieren esfuerzo o se encuentran relacionados con realizar las labores del hogar como, por ejemplo, dependienta, secretaria, criada o prostituta.

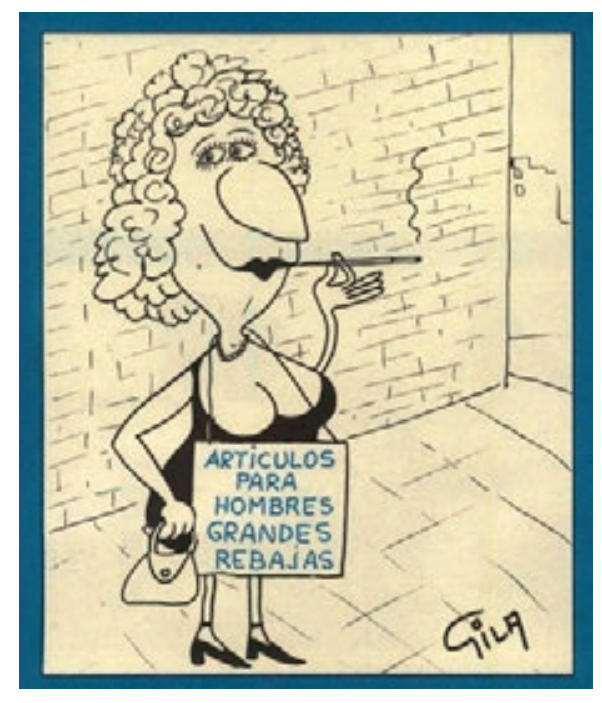

Imagen 5: Las mujeres están reservadas para empleos tradicionalmente asociados al género femenino. Viñeta de Gila, 3 de marzo de 1973. Fuente: Hermano Lobo Digital.

Las viñetas están representadas en plano general, sin perspectiva y con poco color. Respecto a la cantidad de personajes que aparecen en la escena, es bajo, normalmente son diálogos entre dos personas. Estamos ante piezas muy planas y minimalistas, sin distracciones en las que los autores pretenden concentrar la atención en quién lo dice y qué dice. La escasez de detalles de la ilustración viene también justificada por una contextualización de las escenas en situaciones cotidianas, conocidas por el lector con anterioridad. Ganan peso los personajes caracterizados con señas de identidad propias de un grupo social o del rol que desempeñan, reconocibles al público. En el caso de las mujeres, la ropa y el peinado son elementos clave en el reconocimiento del rol que representan, especialmente cuando no tienen voz.

En este contexto, la exageración y la ironía son los recursos presentes en la mayoría de las viñetas, respaldados especialmente por dobles significados y llamadas de atención a través de textos exclamativos. Por ejemplo, se observa el doble significado a través de la palabra apertura asociada a que una mujer aparezca desnuda y a las libertades que supuestamente se iban a conseguir como consecuencia del conocido como Espíritu del 12 de febrero. La exageración también se utiliza para enfatizar situaciones absurdas o que escapan a la lógica. 


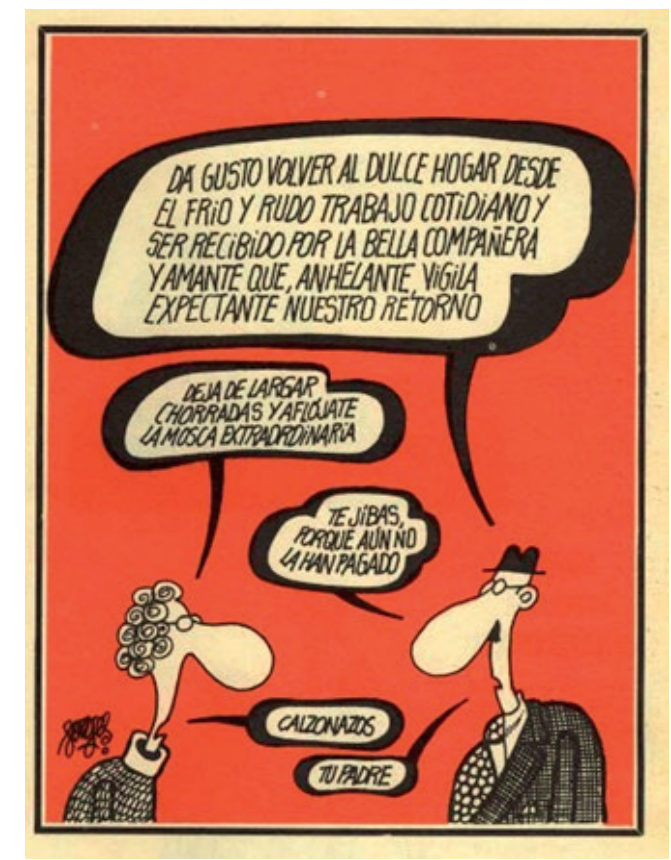

Imagen 6: La ironía, la exageración y el doble significado son los recursos más utilizados en las viñetas de Hermano Lobo. Viñeta de Forges, 23 de diciembre de 1972. Fuente: Hermano Lobo Digital.

El sarcasmo está presente en las viñetas que muestran el maltrato (consentido socialmente) del hombre hacia la mujer, fruto del machismo y del abuso del poder del hombre. Las viñetas son muy explícitas con escenas de gran brutalidad. Observamos en diferentes ejemplos como el hombre ejerce violencia física sobre la mujer con objetos como palos o cuchillos y la presencia de amenazas verbales.

Las temáticas más tratadas en las viñetas en las que las mujeres tienen presencia son las relaciones sentimentales y familiares a través de situaciones costumbristas. Muestran un contexto de la mujer caracterizado por tener límites que impone la sociedad y están representados a través de su entorno más cercano: el matrimonio y la familia. Las relaciones prematrimoniales, prohibidas y castigadas moralmente por la sociedad, aparecen representadas a través de embarazos no deseados. El volumen de viñetas relacionadas con esta temática crece en el último año de la revista mostrando una evolución en la liberación de la mujer, representada en su vertiente más superficial, como es la adopción de una nueva actitud más liberal en las relaciones sentimentales con los hombres.

Sin embargo, el embarazo fuera del matrimonio se representa como una situación polémica ya que las relaciones sexuales antes de casarse no son aceptadas. Como consecuencia, observamos viñetas donde la mujer desea que su embarazo sea interrumpido o intenta esconder de dónde procede (a pesar de ser una evidencia para el lector) para justificar su inocencia dentro del entorno familiar y otros círculos que no comparten esta visión de las relaciones. 


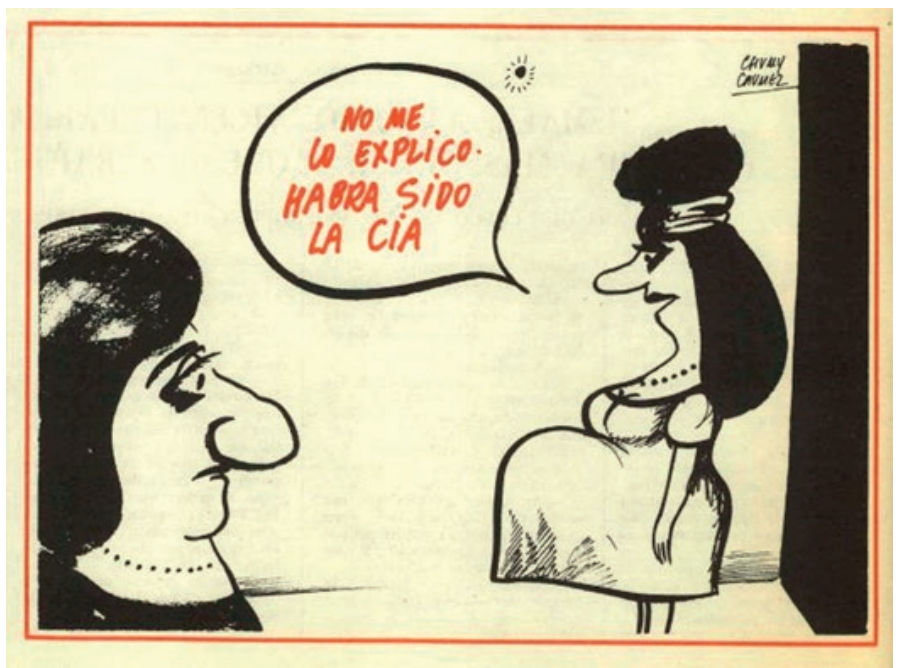

Imagen 7: Las relaciones sentimentales son la temática recurrente de las viñetas en las que aparecen mujeres. Viñeta de Chumy Chúmez, 6 de marzo de 1976. Fuente: Hermano Lobo Digital.

La segunda temática abarca las relaciones matrimoniales. Hermano Lobo presenta la institución matrimonial como unión que dura para siempre basada en escenas violentas que muestran el maltrato hacia la mujer o escenas más agradables, pero que reflejan relaciones muy desgastadas donde el romanticismo no existe. Las relaciones extramatrimoniales aparecen en la revista tanto por parte de la mujer como por parte del hombre, aunque especialmente en el caso del género masculino. En el caso de la mujer, la infidelidad dentro del matrimonio acostumbra a darse en el hogar mientras que el hombre puede manifestarla en otras ubicaciones, se trata de una infidelidad más libre. Asimismo, la mujer siempre es sorprendida por el marido.

El lector y la revista comparten la realidad temporal, consecuentemente, se consigue conectar con el lector a través de la representación de escenas cotidianas reconocibles. La mujer que presenta Hermano Lobo reúne intactos los tópicos sobre la condición y el papel femenino en la sociedad española de los años 70 . La efectividad de las viñetas se concentraría en la liberación del lector a través, no sólo del aspecto lúdico, sino también de la contribución a la reflexión y a la consolidación de sus opiniones en este caso sobre la posición que ocupa la mujer bajo las estructuras del franquismo.

Los humoristas gráficos Summers, Chumy Chúmez, Gila y Forges son los encargados principalmente de caricaturizar de manera disparatada y, en ocasiones con una ironía mordaz, la figura de la mujer a través de las viñetas de Hermano Lobo. Chumy Chúmez y Gila ofrecen la visión más dura y desagradable de la situación de la mujer, mientras que Summers y Forges representan situaciones más amables.

\section{CONCLUSIONES}

Hermano Lobo constituye una revista progresista que reproduce ideas de patriarcado, enfatizadas por la mentalidad dominante del franquismo, siendo testigo del papel secundario que ocupa la mujer en la sociedad. Desde las viñetas del 
semanario de humor, se muestran los tópicos sobre la condición y el papel femenino en la sociedad franquista, una mujer enmarcada en los roles clásicos de ama de casa, madre y esposa. La mujer tiene poca presencia en las viñetas de la revista en comparación con el hombre: aparece como una figura silenciada, ejerciendo un papel secundario respecto al varón o simplemente como figurante.

Las mujeres aparecen atadas sentimentalmente a un hombre y ejerciendo las labores del hogar. Este hecho, explicaría que las escenas femeninas están enmarcadas, en su mayoría, en el hogar y en ambientes familiares. Las únicas excepciones que rescatan a la figura femenina de las tareas domésticas y de la casa son aquellas que representan a la mujer ejerciendo otros empleos, reservados tradicionalmente al género femenino. A pesar de que se deja vislumbrar tímidamente una nueva mentalidad en la revista Hermano Lobo, se perpetúan los papeles asignados a la mujer tradicional.

La reproducción de una figura femenina estereotipada obedecería a la crítica en ocasiones, pero también funcionaría como mero instrumento con intención humorística. Teniendo en cuenta que los lectores de Hermano Lobo estarían en la línea del progresismo contrario al inmovilismo franquista, la efectividad de las viñetas se concentraría no solo en provocar la carcajada, sino también en invitar a reflexionar sobre el papel que la mujer ocupaba en la España de los años 70.

Las mujeres ocuparon un papel secundario en el ejercicio del humor de la revista Hermano Lobo. Por tanto, se reflejaría la realidad de las españolas de los años 70: una mujer que vive subordinada al hombre cuyo lugar se encuentra en el hogar para el ejercicio de su oficio madre, ama de casa y esposa.

\section{REFERENCIAS}

Abella, R. (2006). La vida cotidiana bajo el régimen de Franco. Madrid: Temas de hoy. Historia.

Bordería, E.; Martínez Gallego, F.A. y Gómez Mompart, J. Ll. (dirs.)(2010). La risa periodística. Teoría, metodología e investigaciones en comunicación satírica. Valencia: Tirant lo Blanch.

Conde Martín, L. (2005). El humor gráfico en España. La distorsión intencional. Madrid: APM. Asociación de la Prensa de Madrid.

Fontes, I., Menéndez, M (2004). El Parlamento de Papel. Las revistas españolas en la transición democrática. Madrid: APM. Asociación de la Prensa de Madrid

Galán, D. ¿Reírse de España? El humor español en el banquillo. Fernando Torres Editor: Valencia, 1974.

Gómez Mompart, J.L. (2008). "Historia de la Comunicación e Historia del Periodismo: Enfoques teóricos y metodologías para la investigación". En Martínez Nicolás, M. 
(coord.) (2008). Para investigar la comunicación. Propuestas teórico-metodológicas. Madrid: Tecnos.

Roig, M. (1989). La mujer en la historia. Madrid: Ministerio de Asuntos Sociales. Instituto de la Mujer.

Segado Boj, F. (2011). Un país de chiste. El humor gráfico durante la Transición. Madrid: Rialp.

Segado Boj, F. (2009). "Un tópico perpetuado. La imagen de la mujer y el feminismo en el humor gráfico de la prensa diaria durante la transición (1974-1977)". Revista Zer. Vol. 14 - Núm. 27. pp. 203-224.

Tubau. I. (1987). El humor gráfico en la prensa del franquismo. Barcelona: Editorial Mitre.

Tusell, J., Queipo de Llano, G. (2003). Tiempo de incertidumbre. Carlos Arias Navarro entre el franquismo y la Transición (1973-1976). Barcelona: Crítica Barcelona.

VV.AA. "Hermano Lobo" [en línea]. Mayo 1972 - Noviembre 1976. Disponible en: http://www.hermanolobodigital.com/ (Último acceso: 13/01/2015).

VV.AA (1999). Lo mejor de Hermano Lobo. Semanario de humor dentro de lo que cabe. Madrid: Temas de hoy.

VV.AA (1999). Españolas en la transición. De excluidas a protagonistas (1973 1982). Madrid: Biblioteca Nueva.

\section{AUTORA:}

\section{Carla Garrido Zanón}

Estudiante de doctorado del Área de Periodismo. Desarrollando la tesis "El humor en los últimos años del franquismo e inicios de la transición democrática española: el caso de Hermano Lobo (1972-1976)." Departamento de Teoría de los Lenguajes y Ciencias de la Comunicación. Universidad de Valencia. 